\title{
Mengembangkan Konsep dan Pengukuran Pengasuhan dalam Perspektif Kontekstual Budaya
}

\author{
Developing Concept and Measurement of Parenting \\ in Cultural Contextual Perspective
}

\author{
Agnes Indar Etikawati, Juke Roosjati Siregar, Hanna Widjaja, \& Ratna Jatnika ${ }^{1}$ \\ Fakultas Psikologi Universitas Padjadjaran
}

\begin{abstract}
Beliefs and goals in parenting are influenced by the expectations of society or local culture. Therefore, the measurement of parenting should be developed from a contextual perspective. The development of the measurement conducted inductively which starts with the phase of indigenous concept exploration. In order to obtain accurate concept of parenting from indigenous perspective, participants should be parents living in a particular area, having a local ethnic identity, using local language and customs in their daily lives. Interview or focus group discussion (FGD) with questions that refer to the parenting elements could be used as data collection method. Two alternatives of data analysis could be done to obtain construct at the level of parenting practice or parenting style. The construct is then developed into an instrument by following scale development guidelines. This article is a literature study on the development of concept and measurement for parenting based on indigenous perspective.
\end{abstract}

Keywords: contextual perspective; parenting; scale development

\begin{abstract}
Abstrak. Keyakinan dan tujuan dalam pengasuhan dipengaruhi oleh harapan masyarakat atau budaya setempat. Oleh karena itu pengukuran pengasuhan semestinya dikembangkan dalam perspektif kontekstual. Pengembangan pengukuran pengasuhan dilakukan secara induktif, diawali dengan tahap eksplorasi konsep indigeneous pengasuhan. Untuk mendapatkan konsep pengasuhan yang akurat berdasarkan perspektif indigenous, partisipan dalam fase eksplorasi orang tua yang tinggal di daerah tertentu, memiliki identitas kesukuan setempat, menggunakan bahasa dan adat istiadat budaya setempat dalam kehidupan sehari-hari. Wawancara atau diskusi kelompok dengan pertanyaan yang mengacu pada elemen pengasuhan dapat digunakan sebagai metode pengumpulan data. Dua alternatif analisis data dapat dilakukan untuk mendapatkan konstruk pengasuhan pada tataran praktik pengasuhan atau pola asuh. Setelah dirumuskan, konstruk dapat dikembangkan menjadi instrumen dengan mengikuti pedoman pengembangan skala. Artikel ini merupakan studi literatur terhadap pengembangan konsep dan pengukuran terhadap konstruk pengasuhan berdasarkan perspektif indigenous.
\end{abstract}

Kata kunci: pengasuhan; perspektif kontekstual; pengembangan skala

\footnotetext{
${ }^{1}$ Korespondensi mengenai artikel ini dapat melalui: agnes.indar@gmail.com, jukesiregar@yahoo.co.id, hanf.widjaja@gmail.com, ratna@unpad.ac.id
} 


\section{Pengantar}

Pengasuhan adalah faktor yang tidak dapat dilepaskan dari perkembangan dan kehidupan anak-anak. Topik mengenai pengasuhan atau parenting menjadi topik yang sering menjadi obrolan sehari-hari para orang tua atau di media sosial, dan menjadi topik yang paling diminati dalam penyuluhan atau seminar-seminar untuk para orang tua. Para peneliti pun tampaknya tidak dapat mengabaikan pentingnya faktor pengasuhan sebagai salah satu determinan yang berpengaruh pada perkembangan atau kesehatan mental anak-anak.

Walaupun pengasuhan menjadi topik yang populer namun penelitian-penelitian yang melibatkan pengasuhan dianggap kurang menarik dan ketinggalan zaman. Pengasuhan mencakup berbagai sikap dan perilaku orang tua terhadap anak, namun seringkali konsep dan pengukurannya hanya digambarkan menggunakan konsep pola asuh yang biasanya menggunakan konsep pola asuh dari Baumrind. Konsep dari Baumrind (1966) dikenal dengan model tipologi tripartit yang membedakan pengasuhan menjadi tiga tipe yaitu pola asuh autoritarian, autoritatif dan permisif. Tipologi tripartit kemudian dilengkapi oleh Maccoby \& Martin (1983) menjadi empat tipe pengasuhan yaitu pola asuh autoritarian, autoritatif, permisif dan uninvolved.

Pengukuran dengan konsep pengasuhan dari Baumrind sebenarnya tidak dapat digunakan di semua budaya terlebih di negara-negara dengan budaya kolektivis (García \& Gracia, 2009; Maccoby \& Martin, 1983). Alat ukur tipologi pola asuh dari Baumrind maupun alat ukur dari ahli-ahli lain sesudahnya (Maccoby \& Martin, 1983; Skinner, Johnson, \& Snyder, 2005) dikembangkan dalam budaya barat, yang ditandai dengan adanya dorongan otonom (autonomy support) terhadap anak di dalam dimensi kehangatan (warmth). Dimensi kendali (control) dan kehangatan (warmth) dalam konsep pola asuh dari Baumrind memiliki makna yang berbeda atau bahkan tidak bermakna bagi budaya lain. Perbedaan makna dimensi pengasuhan menjadi salah satu sebab ditemukannya perbedaan hasil penelitian antara budaya-budaya yang berbeda. Sebagai contoh, pola asuh autoritatif berhubungan dengan prestasi akademik remaja di Amerika, namun menjadi kurang berpengaruh di kalangan remaja Asia dan Afrika di Amerika (Darling \& Steinberg, 1993). Quoss \& Zhao (1995) juga menemukan bahwa orang tua Cina lebih otoriter dibanding orang tua Amerika, namun demikian anak-anak di Cina merasa puas terhadap pengasuhan orang tua.

Kedudukan pengasuhan dalam kehidupan anak dapat dilihat dengan jelas dalam perspektif ekologi. Dalam perspektif ekologi, pengasuhan dari orang tua merupakan sistem di lingkungan terdekat atau microsystem anak. Sebagai microsystem anak, pengasuhan berada di bawah pengaruh sistem lingkungan yang lebih luas (macrosystem) yaitu budaya atau nilainilai yang dihidupi oleh masyarakat setempat. Dalam perspektif ekologi, keseluruhan sistem yang melingkupi kehidupan anak akan berubah seiring dengan perkembangan zaman. Perubahan zaman inilah yang disebut sebagai chronosystem (Bronfenbrenner, 1979, 1994). Perspektif ekologi menempatkan konsep pengasuhan secara kontekstual, baik secara kultural maupun waktu. Dengan demikian pengukuran pengasuhan semestinya sesuai dengan budaya setempat dan perkembangan zaman.

Naskah ini disusun agar dapat menjadi salah satu acuan untuk 
mengembangkan konsep dan pengukuran pengasuhan dalam perspektif kontekstual. Naskah ini akan mencakup kajian tentang perkembangan konsep pengasuhan, konsep pengasuhan dalam perspektif kontekstual, dan metode penelitian (eksploratif) untuk memperoleh alat ukur pengasuhan.

\section{Pembahasan}

\section{Hakikat dan Sejarah Konsep Pengasuhan}

Untuk memahami hakikat pengasuhan atau parenting, kiranya perlu menilik asal istilah parenting itu sendiri. Istilah parenting berasal dari bahasa Latin 'parere' yang berarti to bring forth (menghasilkan). Dari asal kata tersebut, maka istilah 'parenting' lebih merujuk pada suatu aktivitas yaitu mengembangkan dan mendidik, bukan sekedar menyangkut siapa yang melakukan (Clarke-Stewart, 2006). Istilah parenting dapat diartikan pula sebagai rangkaian kegiatan yang dilakukan orang tua untuk menjalankan perannya sebagai orang tua. Peran orang tua adalah memberikan perawatan, memberikan dukungan emosional, serta melakukan sosialisasi mengenai keterampilan-keterampilan dan nilai-nilai yang perlu dimiliki anak agar dapat berfungsi sebagai anggota kelompok sosial (Grusec, 2002; Lerner, 1995; Segrin, 2005). Maka dapat ditarik kesimpulan bahwa pengasuhan adalah serangkaian kegiatan yang dilakukan orang tua untuk mencapai perkembangan yang diharapkan pada anak.

Perbincangan mengenai pengasuhan telah dimulai sejak di masa Yunani kuno ketika anak-anak dianggap sebagai bagian yang penting dan integral dari keluarga dan dampak-dampak faktor lingkungan (nurture) terhadap anak mulai mendapat perhatian. Di masa ini telah muncul kesadaran mengenai adanya tahap-tahap pertumbuhan anak dan pemikiran mengenai metode pengasuhan anak yang tepat untuk tahap-tahap tersebut (French, 2002). Terdapat sedikit perbedaan pengasuhan di kota-kota kuno saat itu, yang lebih didasarkan pada relasi orang tua dan anak. Yunani dan Roma menempatkan ayah sebagai figur yang lebih memiliki kekuatan legal terhadap anak, selebihnya peran ayah dan ibu kurang lebih sama yaitu bertanggung jawab terhadap perkembangan fisik dan moral anak, serta pendidikan anak. Dalam keluarga Roma, hubungan antara ayah dan anak perempuan dapat menjadi suatu ikatan yang paling afeksional. Di Spartan, kota kuno yang lain, ayah hampir sepenuhnya meninggalkan keluarga dan anak-anak karena hampir seluruh waktunya digunakan untuk menjalankan tugas sebagai tentara Spartan (French).

Seiring dengan berkembangnya psikologi yang dimulai pada awal abad 20, pembicaraan mengenai peran orang tua terhadap anak menjadi bagian penting dalam teori-teori psikologi. Pengasuhan disinggung dalam dua teori besar yaitu teori perilakuan (behavioristik) dan psikoanalisa. Teori perilakuan menempatkan pengasuhan sebagai strategi orang tua dalam membentuk atau menghasilkan perilaku tertentu pada anak. Teori psikoanalisa menempatkan pengasuhan sebagai konstelasi sikap orang tua pada anak yang menimbulkan suatu pengalaman emosional bagi anak (Darling \& Steinberg, 1993; Lerner, 1995). Kedua teori tersebut lalu diikuti oleh teori-teori lain yang sealiran. Sebagai contoh, teori penerimaan-penolakan dari Rohner (2005) dan teori attachment dari Ainsworth \& Bowlby (1991) merupakan teori yang memiliki pandangan atau paradigma yang sama dengan teori psikoanalisis, yaitu 
paradigma organismik. Paradigma organsimik melihat individu sebagai organisme yang memiliki pengalaman emosional dari interaksi dengan lingkungannya.

Konsep pengasuhan secara eksplisit mulai dikemukakan oleh para ahli dengan menggunakan pendekatan dimensi pola, melibatkan baik proses instrumental yang berasal dari teori perilakuan maupun proses afeksional yang berasal dari teori psikoanalisis (Darling \& Steinberg, 1993; Fletcher, Walls, Cook, Madison, \& Bridges, 2008). Konsep pengasuhan dengan pendekatan dimensional digunakan untuk mempelajari dan menggolongkan variasi normal pengasuhan orang tua ke dalam tipe pola asuh tertentu. Konsep pola asuh yang paling luas digunakan dalam studistudi perkembangan anak adalah konsep pola asuh dari Baumrind (1966), yang melibatkan dua unsur penting dalam pengasuhan yaitu dimensi kendali (control) dan kehangatan (warmth) dan menggolongkan pola asuh menjadi tipe autoritatif, autortarian, permisif dan uninvolved. Walaupun banyak penelitian menunjukkan kesesuian dengan teori dari Baumrind, bahwa pola asuh autoritatif merupakan pengasuhan yang optimal bagi perkembagan anak, namun hal ini tidak ditemukan di populasi dengan budaya yang berbeda.

Pada tahun 1970-an, kognisi orang tua yang meliputi keyakinan dan nilai-nilai dalam pengasuhan mulai mendapat perhatian (Kim, 2006). Adanya pengaruh faktor budaya terhadap keyakinan dan tujuan pengasuhan kemudian memunculkan perspektif kontekstual terhadap pengasuhan. Perspektif kontekstual ini menghasilkan sejumlah konsep pengasuhan yang bersifat asli (indigeneous), seperti misalnya di China (Chao, 1994), di Jepang (White \& LeVine, 1986), di India (Gupta; Seymour, dalam Chao \& Tseng,
2002) dan di Filipina (Russell, Crockett, \& Chao, 2010).

\section{Ragam Perspektif terhadap Pengasuhan}

Pada penjelasan mengenai riwayat konsep pengasuhan telah disinggung adanya beberapa teori yang berkenaan dengan pengasuhan. Teori-teori tersebut mencerminkan adanya beberapa perspektif yang berbeda mengenai pengasuhan. Jika dipetakan, perspektif terhadap pengasuhan dapat dibedakan menjadi perspektif mekanistik, perspektif organismik, perspektif pola dan persektif kontekstual. Berikut adalah penjelasan dari masingmasing perspektif tersebut.

Perspektif mekanistik. Perspektif mekanistik melihat perkembangan manusia sebagai proses yang mengikuti hukum universal seperti mesin. Perspektif mekanistik tercermin dari teori-teori belajar atau teori perilakuan yang mengasumsikan adanya mekanisme S-R (stimulusrespon) (Kim, 2006). Dalam teori perilakuan, pengasuhan anak-anak dilihat sebagai proses pembelajaran seperti di laboratorium dengan prinsip-prinsip pengkondisian atau penguatan. Orang tua adalah orang utama yang mengatur agenda untuk apa anak-anak belajar, melakukan penguatan terhadap perilaku yang diharapkan dan sebaliknya pada perilaku yang tidak diharapkan (Maccoby, 1992).

Pendekatan perilakuan lebih memusatkan perhatian pada berbagai tindakan atau strategi orang tua untuk mencapai tujuan sosialiasi tertentu, sehingga pendekatan ini memunculkan konsep mengenai kendali orang tua (parenting control) dan praktik pengasuhan. Pembicaraan mengenai praktik pengasuhan dibatasi dengan wilayah atau tujuan sosialisasi tertentu, antara lain peningkatan prestasi akademik, regulasi diri atau 
perilaku prososial (Brody \& Flor, 1999; Cheung \& McBride-Chang, 2008; Davis \& Carlo, 2018). Sebagai contoh, ahli (Carlo, Mcginley, Hayes, Batenhorst, \& Wilkinson, 2007) menyebutkan adanya sejumlah teknik dalam praktik disiplin terhadap anak yaitu pemberian reward, modelling, melibatkan anak dalam aktivitas (experiential learning), memberikan penjelasan (inductive reasoning), komunikasi dua arah (discursive communication) dan pemberlakuan aturan (rule setting).

Perspektif organismik. Perspektif organismik melihat manusia sebagai organisme hidup yang aktif berinteraksi dengan lingkungannya. Teori-teori yang tergolong dalam perspektif organismik memberikan penekanan pada interaksi afeksional antara individu (organisme) dan lingkunganya. Teori yang mewakili perspektif organismik ini adalah teori psikoanalisis dari Freud yang memberikan penekanan pada pengalaman emosional anak berkaitan dengan pemenuhan kebutuhan dasar anak (Darling \& Steinberg, 1993; Kim, 2006). Dalam perspektif organismik, hal yang disoroti dalam pengasuhan adalah hal-ikhwal mengenai relasi antara orang tua dan anak. Teori lain yang menggunakan perspektif organismik ini adalah teori penerimaan-penolakan (acceptance-rejection) dari Rohner (2005) dan juga teori attachment dari Ainsworth \& Bowlby (1991).

Perspektif dimensi pola. Perspektif dimesi pola (dimension of pattern) atau yang sering disebut sebagai pola asuh merupakan perspektif yang muncul dari upaya mempelajari variasi normal pengasuhan. Dimensi pengasuhan adalah fitur, kualitas, atau skema deskriptif yang digunakan untuk menggambarkan sifat pengasuhan, sehingga dapat digunakan untuk membuat tipologi pengasuhan (Skinner, Johnson, \& Snyder, 2005).
Perspektif dimensi pola mengkombinasikan antara proses instrumental (control) dan proses afeksional (nurturing) (Darling \& Steinberg, 1993), seperti misalnya pola warmth/hostility dan restrictiveness/ indulgentness (Sears, et al. dan Becker dalam (Fletcher, et al., 2008), pola acceptance-rejection dan pola permissivenessstrictness (Rohner \& Rohner, 1981); kendali (control) dan kehangatan (warmth) (Baumrind, 1966) dan responsiveness dan demandingness (Maccoby \& Martin, 1983).

Rumusan dimensi pola dari Baumrind (1966) dan Maccoby \& Martin (1983) menghasilkan empat penggolongan (tipologi) pola asuh, yaitu tipe autoritatif, tipe autoritarian, tipe permisif dan tipe uninvolved. Sebuah studi yang lebih baru (Skinner, et al., 2005) menemukan adanya enam dimensi dalam pengasuhan yang berkaitan dengan kehangatan (dimensi warmth dan rejection), pemberlakuan struktur (dimensi structure dan chaos) serta dorongan untuk otonom (dimensi autonomy support dan coercion).

Perspektif kontekstual. Perspektif kontekstual melihat perkembangan individu sebagai proses yang melibatkan interaksi antara individu yang berkembang dengan faktor-faktor budaya, histori dan faktor sosial lainnya (Kim, 2006). Pendekatan kontekstual dalam psikologi adalah pendekatan yang menempatkan konteks sebagai kunci untuk menjelaskan berbagai fenomena dan struktur psikologis (Verbitsky \& Kalashnikov, 2013). Teori dalam psikologi yang menggunakan perspektif kontekstual adalah teori ekologi dari Bronfenbrener. Di dalam teori ekologi, pengasuhan ditempatkan sebagai lingkungan terdekat atau microsystem anak yang sedang berkembang, yang tidak dapat dilepaskan dari pengaruh lingkungan yang lebih luas atau macrosystemyaitu budaya setempat. 
Konsep yang dikembangkan dengan perspektif kontekstual memiliki makna khusus bagi masyarakat budaya tertentu dan memiliki makna berbeda bagi budaya yang lain (Wyer, Chiu, \& Hong, 2009). Sebagai contoh, pengasuhan di budayabudaya tertentu seperti di Asia tidak selalu dapat dipotret dengan konsep pola asuh dimensional dari Baumrind. dimensi responsiveness dari Baumrind sebenarnya tdak hanya memuat kehangatan namun juga memuat dorongan untuk otonom. Dorongan otonom inilah yang seringkali tidak sesuai dengan budaya negara-negara di Asia. Contoh lain, konsep kendali dalam pengasuhan bagi masyarakat di Cina yang disebut sebagai guan (to govern) juga memiliki makna kepedulian terhadap anak, berbeda dengan konsep kendali yang ada di masyarakat barat pada umumnya. Ketika kendali (control) dianggap bentuk 'kejahatan' atau penolakan orang tua oleh remaja-remaja di barat, remaja-remaja di Asia justru menganggap kendali orang tua sebagai hal yang lumrah dan bahkan dianggap sebagai bentuk kepedulian orang tua (Grusec \& Goodnow, 1994; Rohner \& Pettengill, 1985; Shek, 2005).

Dengan adanya pendekatan kontekstual, penelitian mengenai pengasuhan kemudian dilakukan untuk menguji adekuasi ideologi pola asuh tradisional dalam menggambarkan populasi di budaya tertentu (Darling \& Steinberg, 1993). Selain itu, efek pola asuh terhadap hasil perkembangan anak juga dipelajari secara kontekstual.

\section{Pengembangan Konsep Pengasuhan dalam Perspektif Kontekstual Budaya}

Salah satu konteks yang sering digunakan dalam mengembangkan konsep pengasuhan adalah konteks budaya. Keyakinan dan tujuan orang tua seringkali dilandasi oleh nilai-nilai atau prescription kultural (Chao, 2000). Dalam studi-studi psikologi, budaya sering dibedakan atas budaya individualis dan budaya kolektivis. Budaya individualis seperti yang banyak ditunjukkan masyakarat di Amerika dan Eropa, lebih menekankan nilai kebebasan pribadi dan cenderung untuk menempatkan tujuan pribadi di atas tujuan kelompok. Di sisi lain, budaya kolektivis seperti di Asia, Afrika dan Amerika Selatan, menekankan harmoni sosial dan cenderung mengorbankan tujuan pribadi untuk tujuan kelompok (Biswas-Diener, Diener, \& Tamir, 2004; Markus \& Kitayama, 1991). Di kalangan masyarakat individualis orang tua mendorong kemandirian, self-assertion, dan rasa mampu (self-agency), sedangkan di masyarakat kolektivis orang tua lebih mendorong anak untuk menghargai otoritas, memiliki rasa tanggung jawab sosial atau rasa keterikatan sosial dan selaras dengan lingkungannya (Kagitcibasi, 2005; Keller \& McDade, 2000; Triandis, 2007; Wise \& da Silva, 2007).

Perspektif kontekstual budaya melandasi munculnya studi-studi indigeneous dalam psikologi. Psikologi indigeneous adalah studi mengenai proses mental manusia yang dilakukan di suatu area tertentu dan hasilnya ditujukan bagi masyarakat di area tersebut (Kim \& Chun, 1994). Dibandingkan dengan psikologi mainstream dengan teori-teori yang bersifat universal, pendekatan psikologi indigeneous lebih mendorong para peneliti untuk berpikir secara kontekstual atau memahami perilaku manusia dalam konteks budaya setempat.

Beberapa penelitian tentang pengasuhan dilakukan dengan konsep indigenous. Salah satu penelitian yang cukup definitif menggambarkan pengasuhan berbasis budaya adalah penelitian 
yang dilakukan pada masyarakat di China (Chao, 2000; Chao, 1994). Orang tua China mengutamakan nilai prestasi selain nilai berbakti dan pengendalian diri. Dengan pendekatan pola asuh dimensional namun tetap berakar pada budaya Confusian di China, pengasuhan di China dirumuskan dalam konsep pola asuh chiao shun dan guan yang berarti to train dan to govern/to love. Kedua dimensi dalam pengasuhan China tidak dapat disepadankan dengan dimensi orthogonal dari Baumrind. Kedua dimensi memiliki makna yang positif, karena keduanya memuat baik unsur kendali maupun kepedulian dan dukungan dari orang tua (Chao, 2000). Praktik pengasuhan yang dilakukan orang tua China antara lain menunjukkan tuntutan, memberikan bimbingan berkelanjutan dan dukungan berupa keterlibatan, dan pengawasan untuk meningkatkan prestasi sekolah anak (Chao, 2000; Cheung \& McBride-Chang, 2008)

Gambaran pengasuhan indigenous yang berbasis pada nilai-nilai budaya setempat juga tampak di beberapa penelitian yang lain seperti Jepang, Filipina dan India. Pengasuhan di Jepang sangat dipengaruhi oleh nilai-nilai harmoni sosial seperti kepekaan sosial, kebaikan (kindness) dan kehalusan (gentleness). Orang tua Jepang juga sangat menekankan kepatuhan dan kesopanan pada orang dewasa atas dasar prinsip sunao (patuh-kooperatif) dalam budaya Jepang (White \& LeVine, 1986). Pengasuhan di Filipina dipengaruhi oleh nilainilai kebersamaan, rasa malu atas kegagalan memenuhi harapan lingkungan dan relasi timbal balik (pakikisama, hiya, and utang na loob). Budaya yang dipegang oleh masyarakat Filipina membuat anggota keluarga Filipina saling mendukung satu sama lain dengan pola asuh yang bersifat resiprokal (Van Campen \& Russell, 2010). Pengasuhan di India sangat dipengaruhi oleh budaya hidup bersama keluarga besar (mitakshara), di mana interdependensi di antara keluargakeluarga yang tinggal dalam satu tempat tinggal sangat kuat. Sejak dini orang tua India mengajarkan anak-anak tentang kedudukan kekerabatan, jenis kelamin, dan urutan kelahiran mereka (Gupta; Seymour, dalam Chao, 2002).

Dalam sepanjang riwayat penelitian tentang pengasuhan, Darling \& Steinberg, (1993) menyimpulkan bahwa pengasuhan dikonseptualisasikan dalam cara yang berbeda di waktu yang berbeda. Dengan pertimbangan tersebut, Darling \& Steinberg mengajukan suatu konsep pengasuhan yang memuat tiga elemen yang terintegrasi satu sama lain yaitu tujuan pengasuhan, pola asuh dan praktik pengasuhan. Tujuan pengasuhan adalah hasil perkembangan pada anak yang diharapkan orang tua dapat tercapai melalui pengasuhan. Tujuan pengasuhan berpengaruh pada anak melalui pola asuh dan praktik pengasuhan. Pola asuh merupakan konstelasi sikap orang tua terhadap anak yang membentuk iklim emosional orang tua-anak, sedangkan praktik pengasuhan adalah cara-cara yang digunakan orang tua untuk mencapai tujuan pengasuhan. Pola asuh menggambarkan konstelasi sikap orang tua atau iklim emosional orang tua-anak dalam berbagai situasi, sedangkan praktik pengasuhan lebih menggambarkan caracara yang digunakan orang tua untuk mencapai tujuan sosialisasi tertentu (Darling \& Steinberg, 1993).

Tujuan pengasuhan meliputi sejumlah keterampilan, regulasi diri, dan nilai-nilai. Tujuan pengasuhan terkait dengan keyakinan atau prinsip orang tua yang dipengaruhi oleh harapan masyarakat dan 
faktor budaya. Selanjutnya tujuan pengasuhan akan mempengaruhi anak melalui pola asuh dan praktik pengasuhan yang dilakukan orang tua. Dengan model pengasuhan integratif dari Darling \& Steinberg (1993) memungkinkan pengasuhan dikonseptualisasikan sesuai dengan prinsip-prinsip budaya setempat. Dengan adanya tiga elemen pengasuhan secara integratif, maka konsep pengasuhan secara umum (generik) dapat dirumuskan sebagai; sejumlah cara yang dilakukan orang tua untuk mencapai tujuan yang diyakini baik bagi anak dalam suatu iklim emosional. Model pengasuhan integratif dari Darling \& Steinberg ini memungkinkan konsep pengasuhan dirumuskan secara kontekstual.

\section{Langkah-langkah Mengembangkan Alat Ukur Pengasuhan Berbasis Budaya}

Seperti yang telah dipaparkan di atas, keyakinan dan tujuan dalam pengasuhan tidak dapat terlepas dari harapan masyarakat dan nilai-nilai budaya setempat. Oleh karena itu pengukuran pengasuhan semestinya disusun secara kontekstual. Alat ukur pengasuhan yang sesuai dengan budaya setempat akan memberikan gambaran pengasuhan yang tepat dan hasil penelitian yang akurat.

Langkah-langkah pengembangan alat ukur dapat mengacu pada saran Hinkin, Tracey, \& Enz (1997), yang meliputi penyusunan aitem, pemeriksaan isi alat ukur, ujicoba alat ukur dan pemeriksaan properti psikometrik. Penyusunan aitem untuk alat ukur pengasuhan berbasis budaya dilakukan secara induktif karena diawali dengan identifikasi konstruk pengasuhan yang dilandasi nilai-nilai atau prinsip budaya setempat. Karena identifikasi konstruk merupakan langkah penting dalam pengembangan alat ukur pengasuhan, maka identifikasi konstruk dapat ditempatkan sebagai langkah awal dalam pengembangan alat ukur.

Identifikasi konstruk pengasuhan berbasis budaya. Penyusunan aitem untuk alat ukur pengasuhan berbasis budaya dilakukan secara induktif, yaitu diawali dengan studi eksploratif untuk mendapatkan konstruk pengasuhan. Studi eksploratif untuk mendapatkan konstruk terdiri dari pengumpulan data dan analisis data secara kualitatif. Pengumpulan data dalam studi eksploratif dapat dilakukan dengan metode wawancara atau diskusi kelompok (FGD). Partisipan yang diharapkan dalam wawancara atau $F G D$ adalah orang tua dengan identitas kesukuan setempat. Selain dari garis keturunan, identitas kesukuan ditunjukkan dengan adanya praktik budaya yang masih dilakukan seperti penggunaan bahasa daerah dan adat istiadat budaya setempat (custom) dalam kehidupan sehari-hari. Sebagai contoh, responden bersuku Jawa semestinya menggunakan bahasa Jawa untuk berkomunikasi sehari-hari dan menjalankan tata krama Jawa (unggah-ungguh) dalam interaksi sehari-hari.

Pertanyaan kunci yang disampaikan dalam wawancara atau FGD mengacu pada konsep umum pengasuhan dari Darling \& Steinberg (1993), yaitu meliputi pertanyaan mengenai tujuan dan cara-cara yang digunakan orang tua dalam pengasuhan. Pertanyaan berikut dapat disampaikan secara berurutan; “Nilai-nilai atau hal penting apa dalam budaya setempat yang dirasa perlu untuk ditanamkan pada anak?", “Perilaku seperti apa yang mencerminkan nilai tersebut?", "Mengapa nilai-nilai tersebut dianggap penting untuk diajarkan pada anak?", dan "Bagaimana nilai-nilai tersebut dikembangkan dalam perilaku anak?". Beberapa penelitian, antara lain yang dilakukan di Jepang (Shigaki, 1983; 
White \& LeVine, 1986) menggunakan pertanyaan mengenai gambaran anak yang baik atau gambaran anak yang diinginkan sebagai hasil pendidikan. Peneliti perlu menanyakan perilaku apa saja yang mencerminkan suatu nilai untuk mendapatkan pemahaman yang tepat mengenai nilai yang dimaksud. Sebagai contoh, dalam suatu penelitian di Jepang (White \& LeVine; 1986) diperoleh informasi bahwa nilai sunao memiliki makna yang lebih positif dibanding arti harafiahnya (kepatuhan), yaitu lebih pada sikap kooperatif yang muncul secara alamiah dari hati anak-anak. Para responden tidak menganggap sunao sebagai nilai yang berlawanan dengan nilai genki (aktif-energik).

Mempertimbangkan konsep pengasuhan dari Darling \& Steinberg (1993) maka terdapat dua pilihan konstruk pengasuhan; konstruk pengasuhan pada tataran praktik pengasuhan dan konstruk pengasuhan pada tataran pola asuh. Untuk memperoleh konstruk pengasuhan pada tataran praktik pengasuhan, peneliti cukup melakukan kategorisasi data berdasarkan cara-cara yang dilakukan orang tua untuk mencapai tujuan pengasuhan tertentu atau tujuan pengasuhan umumnya di suatu kelompok masyarakat. Penamaan kategori praktik pengasuhan dapat mengacu pada literatur terdahulu berkenaan dengan praktik pengasuhan tradisional, selebihnya dapat ditentukan oleh peneliti sendiri sebagai suatu temuan baru. Sebagai contoh, praktik pengasuhan tradisional yang dilakukan secara khusus untuk mengembangkan rasa hormat pada anak-anak suku Jawa terdiri dari penanaman rasa takut (wedi), rasa malu (isin) dan rasa sungkan (Geertz, 1983; Suseno, 1984), sedangkan praktik pengasuhan Jawa yang lebih umum meliputi; 1) mengajarkan kepatuhan dan kesopanan 2) memberi perintah terperinci 3) membelokkan dari tujuan yang tidak diharapkan, 4) menakut-nakuti anak dengan akan adanya suatu bahaya dari luar, 5) menjanjikan hadiah, 6) menghukum atau mendiamkan anak (dipunsatru), 7) memenuhi keinginan atau menyuruh anak melakukan hal yang dilarang (dipun-lulu) (Geertz, 1983; Koentjaraningrat, 1984).

Untuk memperoleh konstruk pengasuhan pada tataran pola asuh, peneliti harus melakukan analisis lebih lanjut guna mendapatkan dimensi-dimensi dari keseluruhan praktik pengasuhan. Pola asuh adalah iklim emosional dalam relasi orang tua - anak yang tercermin melalui tindakan-tindakan orang tua (Darling \& Steinberg, 1993). Untuk menghasilkan dimensi pengasuhan, diperlukan abstraksi atau review lebih lanjut seperti yang disebut Strauss \& Corbin (2000) sebagai tahap axial coding. Sebagai contoh, keseluruhan cara-cara pengasuhan dalam keluarga Jawa dapat dipilah ke dalam tiga pola yaitu pola mendorong, pola menghambat dan pola membiarkan (Idrus, 2012). Sebuah review terhadap bentukbentuk praktik pengasuhan di Cina (Chao, 1994), menghasilkan temuan mengenai adanya dimensi chiao shun (to train) dan dimensi guan (to govern/to love).

Penyusunan aitem-aitem. Setelah dirumuskan, selanjutnya konstruk pengasuhan yang terdiri dari aspek-aspek ataupun dimesi-dimensi pengasuhan dapat dikembangkan menjadi alat ukur, pada umumnya berupa skala. Dalam merumuskan pernyataan menjadi aitem-aitem, terdapat beberapa hal yang harus diperhatikan. aitem hanya memuat satu isu, tidak memuat dua atau lebih ide (double barreled questions). Pernyataan dirumuskan secara sederhana dan sesingkat mungkin dengan bahasa dan istilah-istilah yang familiar 
bagi subjek target. Selain penyusunan aitem, perlu ditentukan format penskalaan aitem. Dalam penelitian survei, skala Likert merupakan format skala yang paling umum digunakan. Walaupun biasanya digunakan untuk mengukur sikap, dengan rentang pilihan "completely disagree" hingga "completely agree", namun untuk tujuan pengukuran yang berbeda tipe pilihan lain dapat digunakan dengan range pilihan yang kurang lebih setara (DeCoster, 2005).

Pemeriksaan isi skala. Aitem-aitem yang telah disusun oleh peneliti perlu dinilai oleh orang lain, dalam hal ini ahli yang relevan, untuk memastikan bahwa aitemaitem mencerminkan aspek-aspek variabel yang hendak diukur. Penilaian isi juga dilakukan untuk memastikan bahwa aitem-aitem dapat dipahami oleh subjek penelitian dan tidak menimbulkan kerancuan (bias) pemahaman. Untuk tujuan yang kedua ini, dapat dilakukan pre-test alat ukur pada sejumlah kecil sampel yang serupa dengan populasi penelitian.

Pengumpulan data uji coba skala. Setelah dilakukan penilaian secara isi dan dilakukan perbaikan pada aitem-aitem, selanjutnya dilakukan uji coba pada alat ukur untuk memperoleh data yang nantinya akan dianalisis secara statistik. Agar dapat dilakukan analisis statistik (analisis faktor), jumlah responden (sample size) yang disarankan adalah sepuluh kali atau minimal empat kali jumlah aitem (Schwab; Rumel dalam Hinkin,et al., 1997).

Analisis statistik untuk mendapatkan properti statistik. Properti psikometrik yang diperoleh dengan analisis statistik meliputi validitas dan reliabilitas alat ukur. Langkah analisis yang pertama adalah memeriksa korelasi aitem-total. Korelasi yang rendah menunjukkan bahwa aitem tidak dapat diandalkan dan semestinya tidak digunakan. Langkah analisis yang kedua adalah memeriksa validitas konstruk, dilakukan dengan confirmatory factor analysis (CFA). Hasil CFA memberikan informasi mengenai kesesuaian (fit) model pengukuan dan nilai factor loading setiap aitem dalam mencerminkan dimensinya (Thompson, 2007). Langkah analisis yang ketiga adalah memeriksa reliabilitas alat ukur, dilakukan dengan penghitungan koefisien alpha cronbach.

\section{Penutup}

Pengasuhan memiliki konsep yang luas. Pengasuhan mencakup kegiatan atau caracara yang digunakan orang tua untuk mencapai perkembangan (outcome) pada anak. Para peneliti terdahulu menggunakan berbagai pendekatan untuk merumuskan konsep dan melakukan pengukuran pada pengasuhan, dan konsep yang paling banyak digunakan dalam pengukuran pengasuhan adalah konsep pola asuh dari Baumrind.

Walaupun penelitian-penelitian di barat menunjukkan bahwa pola asuh autoritatif merupakan pengasuhan yang ideal bagi perkembangan anak, namun sejumlah penelitian di budaya lain menunjukkan hasil yang berbeda. Konsep pola asuh dari Baumrind tidak dapat dipergunakan pada populasi dengan budaya lain, dalam hal ini pada budaya kolektivis. Dalam melakukan pengasuhan orang tua memiliki tujuan dan cara-cara mengasuh yang dipengaruhi keyakinan dan nilai-nilai budaya. Oleh karena itu, pengukuran pengasuhan semestinya disusun secara kontekstual sesuai budaya setempat.

Dalam pendekatan kontekstual budaya, pengembangan alat ukur semestinya dilakukan secara induktif. Pengembangan alat ukur diawali dengan studi eksploratif 
untuk mendapatkan (identification) konstruk pengasuhan indigeneous atau pengasuhan berbasis budaya setempat. Konstruk alat ukur pengasuhan dapat dijabarkan dalam aspek-aspek praktik pengasuhan atau dimensi-dimensi pola asuh. Konstruk yang telah dirumuskan kemudian dikembangkan menjadi alat ukur. Pengembangan alat ukur pengasuhan dapat mengikuti langkah-langkah yang disarankan oleh ahli, yaitu meliputi penyusunan aitem-aitem, pemeriksaan validitas isi, pengumpulan data uji coba, dan analisis statistik untuk mendapatkan properti psikometrik.

\section{Daftar Pustaka}

Ainsworth, M. D. S., \& Bowlby, J. (1991). An ethological approach to personality development. American Psychologist, 46(4), 331-341. doi: 10.1037/0003$\underline{066 x .46 .4 .333}$

Baumrind, D. (1966). Effects of authoritative parental control on child behavior. Child Development, 22(2), 345-347. doi: 10.2307/1126611

Biswas-Diener, R., Diener, E., \& Tamir, M. (2004). The psychology of subjective well-being. Daedalus, 133(2), 18-25. doi: $10.1162 / 001152604323049352$

Brody, G. H., \& Flor, D. L. (1999). Linking maternal efficacy beliefs, developmental goals, parenting practices, and child competence. Child Development, 70(5), 1197.

Bronfenbrenner, U. (1979). The ecology of human development experiments: by nature and design. Cambridge: Harvard University Press.

Bronfenbrenner, U. (1994). Ecological models of human development. In T. Husten \& T. N. Postlethwaite (Ed.), International encyclopedia of education (2nd ed., pp. 1643-1647). New York: Elsevier Science.

Carlo, G, Mcginley, M., Hayes, R., Batenhorst, C., \& Wilkinson, J. (2007). Parenting styles or practices? Parenting, sympathy, and prosocial behaviors among adolescents. The Journal of Genetic Psychology, 168(2), 147-176. doi: 10.3200/GNTP.168.2.147$\underline{176}$

Chao, R. \& Tseng, V. (2002). Parenting of Asians. In M. H. (Ed. Bornstein (Ed.), Handbook of parenting: Social conditions and applied parenting (pp. 59-93). New Jersey: Lawrence Erlbaum Associates Publishers.

Chao, R. K. (1994). Beyond parental control and authoritarian parenting style: Understanding Chinese parenting through the cultural notion of training. Child Development, 65(4), 1111-1119. doi: $\underline{10.2307 / 1131308}$

Chao, R. K. (2000). The parenting of immigrant Chinese and European American mothers: relations between parenting styles, socialization goals, and parental practices. Journal of Applied Developmental Psychology, 21(2), 233-248. doi: 10.1016/S01933973(99)00037-4

Cheung, C. S., \& McBride-Chang, C. (2008). Relations of perceived maternal parenting style, practices, and learning motivation to academic competence in Chinese children. Merrill-Palmer Quarterly, 54(1), 1-22. doi: 10.1353/ mpq.2008.0011

Clarke-Stewart, A. (2006). What have we learned: Proof that families matter, policies for families and children, prospects for future research. In J. Clarke-Stewart, A., \& Dunn (Ed.), Families count (pp. 321-336). London: Cambridge University Press. 
Darling, N., \& Steinberg, L. (1993). Parenting style as context: An integrative model. Psychological Bulletin, 113(3), 487-496. doi: 10.1037/ 0033-2909.113.3.487

Davis, A. N., \& Carlo, G. (2018). The roles of parenting practices, sociocognitive/emotive traits, and prosocial behaviors in low-income adolescents. Journal of Adolescence, 62(October 2017), 140-150. doi: 10.1016/j.adolescence.2017.11.011

DeCoster, J. (2005). Scale construction notes (Retrived 4). Retrieved from http://www.stat-help.com/scale.pdf

Fletcher, A. C., Walls, J. K., Cook, E. C., Madison, K. J., \& Bridges, T. H. (2008). Parenting style as a moderator of associations between maternal disciplinary strategies and child wellbeing. Journal of Family Issues, 29(12), 1724-1744. doi: 10.1177/0192513 $\underline{\mathrm{X} 08322933}$

French, V. (2002). History of parenting: The ancient mediterranean world. In M. H. Bornstein (Ed.), Handbook of parenting vol. 2 biology and ecology of parenting (2nd ed., pp. 345-376). New Jersey: Lawrence Erlbaum Associates, Inc.

García, F., \& Gracia, E. (2009). Is always authoritative the optimum parenting style? Evidence from Spanish families. Adolescence, 44(173), 101-131. Retrieved from https://www.ncbi.nlm.nih.gov/pubme $\underline{\mathrm{d} / 19435170}$

Geertz, H. (1983). Keluarga Jawa. Jakarta: Grafiti Press.

Grusec, J.E. (2002). Parental socialization and children's acquisition of values. In M. H. Bornstein (Ed.), Handbook of parenting, vol. 5 practical issues in parenting (2nd ed.). New Jersey:
Lawrence Erlbaum Associates, Inc.

Grusec, J. E., \& Goodnow, J. J. (1994). Impact of parental discipline methods on the child's internalization of values: A reconceptualization of current points of view. Developmental Psychology, 30(1), 4-19. doi: 10.1037/ 0012-1649.30.1.4

Hinkin, T. R., Tracey, J. B., \& Enz, C. A. (1997). Scale construction: Developing reliable and valid measurement instruments. Journal of Hospitality $\mathcal{E}$ Tourism Research, 21(1), 100-120. doi: $\underline{10.1177 / 109634809702100108}$

Idrus, M. (2012). Pendidikan karakter pada keluarga Jawa. Jurnal Pendidikan Karakter, 2(2), 118-130.

Kagitcibasi, C. (2005). Autonomy and relatedness in cultural context implications for self and family. Journal of Cross-Cultural Psychology, 36(4), 403-422. doi: 10.1177/00220 22105275959

Keller, J. D., \& McDade, K. (2000). Attitudes of low-income parents toward seeking help with parenting: Implications for practice. Child Welfare, 79(3), 285-312.

Kim, J. (2006). Korean parents' disciplinary practices and socioeconomic status: An investigation based on disciplinary domains and language functions. University of North Carolina at Greensboro.

Kim, U., \& Chun, M. B. J. (1994). Educational "success" of Asian Americans: An indigenous perspective. Journal of Applied Developmental Psychology, 15(3), 329339. doi: 10.1016/0193-3973(94)90035-3

Lerner, R. M. (1995). America's Youth in crisis: Challenges $\mathcal{E}$ options for programs E policies. doi: $\underline{10.4135 / 9781483327167}$ 
Maccoby, E. E., \& Martin, J. A. (1983). Socialization in the context of the family: Parent-child interaction. In \& E. M. H. P. H. Mussen (Ed.), Handbook of child psychology: Vol. 4. Socialization, personality, and social development (Eds, pp. 1-101). New York: Wiley.

Maccoby, E. E. (1992). The role of parents in the socialization of children: An historical overview. Developmental Psychology, 28(6), 1006-1017. Retrieved from sci-hub.tw/10.1037/0012$\underline{1649.28 .6 .1006}$

Markus, H. R. \& Kitayama, S. (1991). Culture and the self: Implications for cognition, emotion, and motivation. Psychological Review, 98(2), 224-253. doi: 10.1037/0033-295x.98.2.224

Quoss, B. \& Zhao, W. (1995). Parenting styles and children's satisfaction with parenting in China and the United States. Journal of Comparative Family Studies. Retrieved from https://www.jstor.org/stable/41602383? seq=1\#metadata info tab contents

Rohner, R. P., \& Pettengill, S. M. (1985). Perceived parental acceptancerejection and parental control among Korean adolescents. Child Development, 56(2), 524-528. doi: 10.1111/j.14678624.1985.tb00125.x

Rohner, R. P. (2005). Glossary of significant concepts in parental acceptance-rejection theory. Handbook for the study of parental acceptance and rejection, 379-397.

Rohner, R. P. \& Rohner, E. C. (1981). Education Parental AcceptanceRejection and Parental Control: CrossCultural. Ethnology, 20(3), 245-260. doi: $10.2307 / 3773230$

Russell, S. T., Crockett, L. J., \& Chao, R. K. (2010). Asian American Parenting and Parent-Adolescent Relationships. New
York, NY, US: Springer Science + Business Media. doi: 10.1007/978-14419-5728-3

Segrin, C., \& F. J. (2005). Family communication (2nd ed.). New York: Routledge.

Shek, D. T. L. (2005). Perceived parental control and parent-child relational qualities in chinese adolescents in Hong Kong. Sex Roles, 53(9), 7-16.

Shigaki, I. S. (1983). Child care practices in Japan and the United States: How do they reflect cultural values in young children? Young Children, 38(4), 13-24.

Skinner, E., Johnson, S., \& Snyder, T. (2005). Six dimensions of parenting: A motivational model. Parenting, 5(2), 175-235. doi: 10.1207/s15327922 par0502_3

Strauss, A., \& Corbin, J. (2000). Basics of qualitative research techniques. Thousand Oaks, CA: Sage publications.

Suseno, F. M. (1984). Sebuah analisa falsafi tentang kebijaksanaan hidup orang Jawa. Jakarta: Gramedia Pustaka Utama.

Thompson, B. (2007). Exploratory and confirmatory factor analysis: Understanding concepts and applications. Applied Psychological Measurement, 31(3), 245-248. Retrieved from

http://citeseerx.ist.psu.edu/viewdoc/do wnload?doi=10.1.1.920.8902\&rep=rep1 \&type $=p d f$

Triandis, H. (2007). Culture and psychology: A history of their relationship. In D. Kitayama, S., \& Cohen (Ed.), Handbook of Cultural Psychology (Eds), pp. 59-76). New York: Guilford.

Van Campen, K. S., \& Russell, S. T. (2010). Cultural differences in parenting 


\section{ETIKAWATI, DKK}

practices: What Asian American families can teach us. Frances McClelland Institute for Children, Youth, and Families ResearchLink, 2(1), 1-4.

Verbitsky, A. A., \& Kalashnikov, V. G. (2013). Contextual approach in psychology. European Scientific Journal, 9(32), 1-12.

White, M. I., \& LeVine, R. A. (1986). What is an "ii ko" (good child)? In \& K. H. H. W. Stevenson, H. Azuma (Ed.), A series of books in psychology. Child development and education in Japan (pp. 55-62). New York: W H Freeman/Times Books/ Henry Holt \& Co.

Wise, S., \& da Silva, L. (2007). Differential parenting of children from diverse cultural backgrounds attending child care. Melbourne.

Wyer, R. S., Chiu, C. Y., \& Hong, Y. Y. (2009). Understanding culture: Theory, research, and application. Psychology Press. 